\title{
Desenvolvimento e Avaliação de uma Tocha de Soldagem Inteligente
}

\author{
Gabriel de Simas Asquel ${ }^{1}$ (D) , Tiago Vieira da Cunha $^{1}$ (D) \\ ${ }^{1}$ Universidade Federal de Santa Catarina - UFSC, Centro Tecnológico de Joinville, Joinville, SC, Brasil
}

Como citar: Asquel GS, Cunha TV. Desenvolvimento e avaliação de uma tocha de soldagem inteligente. Soldagem \& Inspeção. 2019;24:e2413. https://doi.org/10.1590/0104-9224/SI24.13

\begin{abstract}
Resumo: A soldagem de estruturas destinadas à construção naval em estaleiros é realizada, em sua maioria, de forma manual no cenário brasileiro. Assim como em qualquer aplicação, nesta os parâmetros de soldagem devem ser ajustados conforme a posição de soldagem a fim de garantir a qualidade desejada da união. Todavia, na prática o que se observa é que esta regulagem é continuamente negligenciada devido à falta de preparo dos profissionais envolvidos ou, em uma tentativa de diminuir o tempo de máquina parada durante a operação. Neste contexto, o presente trabalho tem por objetivo apresentar o desenvolvimento de uma tocha de soldagem capaz de reconhecer sua orientação no espaço e, por meio de uma interface com a fonte de soldagem, selecionar automaticamente os parâmetros do processo de acordo com a posição de soldagem em que a mesma se encontra. A fim de avaliar o desempenho do protótipo desenvolvido, foram realizados ensaios de soldagem alternando-se entre as posições 1G, 2G, 3G e 4G. Nestes, o protótipo apresentou um funcionamento adequado às aplicações de soldagem, sendo capaz de reconhecer não somente a posição na qual a soldagem está sendo executada, mas também, de controlar os parâmetros de soldagem presentes na fonte de energia.

Palavras-chave: Tocha de soldagem; Identificação; Posição de soldagem; Soldagem manual; Parâmetros de soldagem.

\section{Development and Evaluation of a Smart Welding Torch}

Abstract: Welding of structures intended for shipbuilding in Brazilian shipyards is often carried out manually. The welding parameters should be adjusted according to the welding position to ensure the quality of the welding joint. However, this adjustment is frequently ignored due to the lack of preparation of professionals or to reduce the machine's downtime. In this context, the present work aims to present the development of a welding torch capable of recognizing its orientation within space and use an interface with the welding power supply to select the parameters according to the welding position. In order to evaluate the performance of the developed prototype, welding tests were carried out alternating welding positions 1G, 2G, 3G, and 4G. The prototype worked well for welding applications, being able to recognize not only the position but also to control the welding parameters on the welding power supply.
\end{abstract}

Key-words: Welding torch; Identification; Welding position; Manual welding; Welding parameters.

\section{Introdução}

Dentre os processos de união de materiais, a soldagem se destaca como o mais importante e abrangente, sendo fundamental desde a microeletrônica até a construção de embarcações de grande porte. Especificamente na construção naval, normalmente são utilizados os processos de soldagem a arco voltaico, entre os quais, destacam-se os processos GMAW, FCAW e SAW. Independente do processo empregado, os parâmetros de soldagem devem ser ajustados conforme a posição de soldagem, a fim de assegurar a qualidade do cordão de solda produzido. Neste contexto, a soldagem de um bloco destinado à construção naval engloba as principais posições de soldagem, necessitando que esses parâmetros sejam regularmente reconfigurados. Todavia, esse ajuste é continuamente negligenciado pelos operadores, devido à falta de preparo dos profissionais envolvidos ou numa tentativa de reduzir o tempo de máquina parada.

Mesmo em estaleiros brasileiros de grande porte a soldagem é realizada, em sua maioria, de forma manual. A automatização dos processos de soldagem nas indústrias de construção naval não é trivial, devido principalmente à produção não seriada de embarcações e às suas geometrias dificultarem o acesso de equipamentos. Neste contexto, a automatização dos processos de soldagem no setor naval tem sido tema de pesquisas a anos. Em 1989, Ivica Mandić et al. [1] analisaram a introdução de robôs soldadores em estaleiros. O ganho de produtividade se destacou entre os indicadores avaliados, porém se constatou a dificuldade da implantação do projeto na linha de produção principal, onde seria preciso dois robôs e um deles exigiria a presença de até 7 graus de liberdade. Em um estudo realizado em um dos maiores estaleiros de Singapura,

Recebido: 01 Mar., 2019. Aceito: 03 Jun., 2019.

E-mails: gabriel.s.asquel@gmail.com (GSA), t.cunha@ufsc.br (TVC)

Este é um artigo publicado em acesso aberto (Open Access) sob a licença Creative Commons Attribution Non-Commercial, que permite uso, distribuição e reprodução em qualquer meio, sem restrições desde que sem fins comerciais e que o trabalho original seja corretamente citado. 
Niculescu et al. [2] discutem e apresentam os benefícios e requisitos da implantação de um robô soldador para com a produtividade da companhia e a diminuição dos riscos à saúde dos operários. Novamente, a complexidade e a versatilidade do local de trabalho, haja vista que muitas vezes possui limite de altura ou necessita do uso de plataforma elevatória, representaram um desafio aos requisitos de projeto. Por vezes carecendo da diminuição da massa do robô ou exigindo uma maior robustez da estrutura automatizada.

O desenvolvimento de um sistema robótico capaz de ser ensinado sobre as manobras de soldagem e que, posteriormente, repete os movimentos do soldador, batizado de SWERS (Ship Welding Robot System), foi apresentado e discutido por Ang et al. [3]. Esse dispositivo é composto por um robô de 6 graus de liberdade montado sobre um guindaste de pórtico de 3 graus de liberdade. Realça-se, no entanto, a criação de um banco de dados dos parâmetros de soldagem e seus respectivos valores de acordo com cada posição e movimento ensinado ao robô. Assim, caso o sistema reconheça que está realizando a soldagem numa determinada posição, os parâmetros mais adequados serão selecionados automaticamente, não sendo preciso interromper o processo para a configuração do equipamento. Entre os parâmetros configuráveis estão a corrente de soldagem, a tensão de soldagem, a velocidade do arame e o comprimento do arame (stickout). Os resultados de ensaios de soldagem com este sistema evidenciaram maior qualidade das juntas soldadas se comparado com a soldagem manual, além de aumentar a velocidade do processo.

O trabalho de Li et al. [4] descreve o desenvolvimento preliminar de um sistema de soldagem orbital que visa identificar a posição da tocha e servir como fonte de controle e otimização dos parâmetros do processo. Conforme os autores, a posição de soldagem ao longo da tubulação pode ser aproximada com o uso de sensores inerciais. No entanto, a estimativa da velocidade de soldagem demanda algoritmos mais complexos baseados em álgebra e cálculo vetorial. Os autores destacam que foi possível calcular a aceleração e velocidade da tocha em movimentos não contínuos, porém, durante a soldagem orbital completa, tornou-se impossível distinguir os dados da aceleração gravitacional e da própria tocha de soldagem. Sendo necessário tecnologias de sensores diferentes e mais modernas daquelas utilizadas no trabalho.

Com base no exposto, o presente trabalho apresenta o desenvolvimento e avaliação de desempenho de uma tocha de soldagem inteligente, constituindo numa alternativa ao setor naval brasileiro frente ao alto custo de implantação de sistemas robotizados. Equipada com um sensor capaz de medir a aceleração agindo sobre o dispositivo, a tocha de soldagem é capaz de reconhecer sua orientação no espaço, e por meio do processamento dos dados e de uma interface de comunicação com a fonte de soldagem, selecionar automaticamente os parâmetros do processo na fonte de acordo com a posição de soldagem que a tocha se encontra. Dessa forma, reduz-se a possibilidade de serem utilizadas as configurações inadequadas e a necessidade de o soldador alterar os parâmetros de soldagem manualmente, permitindo um processo sem interrupções.

\section{Desenvolvimento do Dispositivo}

\subsection{Tocha de soldagem e sistema de coordenadas}

No desenvolvimento do protótipo do dispositivo foi utilizada uma tocha de soldagem GMAW comercial, em cuja face superior do punho foi fixado o compartimento, fabricado por manufatura aditiva, que abriga o sensor e a Interface Homem-Máquina (IHM) do dispositivo, conforme mostra a Figura 1b. Este compartimento se fez necessário uma vez que o espaço restrito no interior do punho da tocha não permitiu alocar o sensor de forma a conciliar seus eixos com a orientação da peça de trabalho. Isto tendo em vista que o sensor precisa estar orientado paralelamente com a superfície a ser soldada. Desta forma, no interior do compartimento se construiu um suporte com o ângulo necessário para corrigir o posicionamento do sensor. A medição do ângulo foi realizada com auxílio de um software de processamento de imagem, resultando em um ângulo de aproximadamente 33으, como mostrado na Figura 1 a.
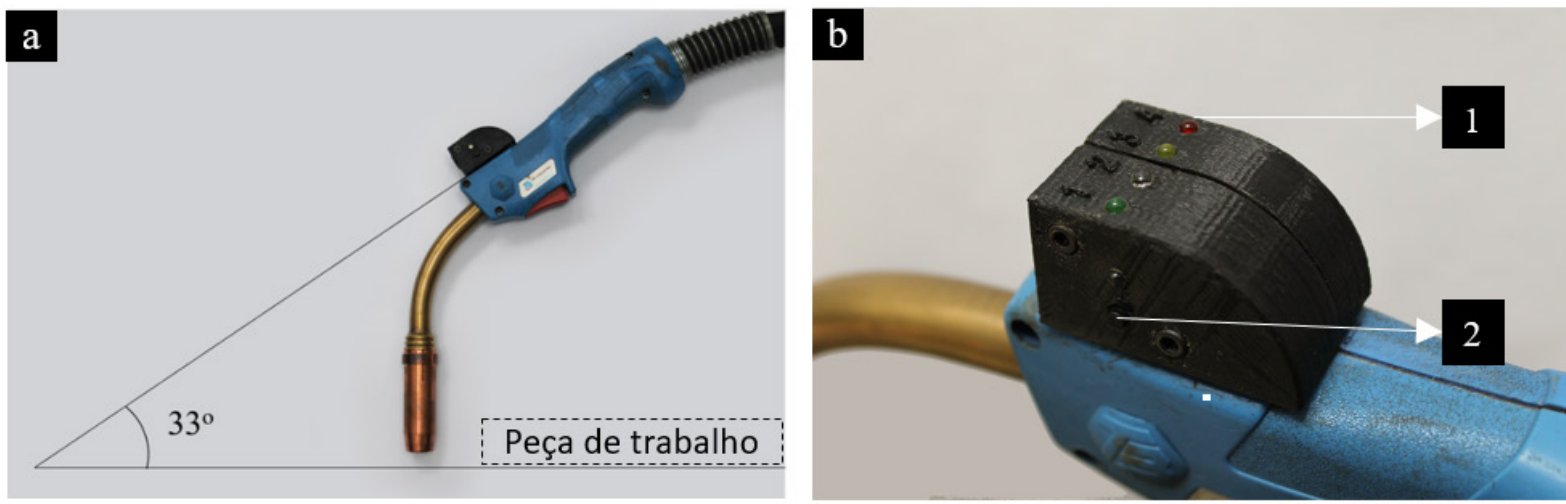

Figura 1. Em (a) medição e representação do ângulo entre a posição do dispositivo no punho da tocha e soldagem superfície a ser soldada. Em (b) tocha de soldagem com o compartimento do dispositivo acoplado: (1) LEDs indicativos da posição de soldagem, (2) botão de seleção de modo de operação. 
O dispositivo desenvolvido considera um sistema de coordenadas composto por três eixos ortogonais, estabelecendo a referência espacial em X, Y e Z. A aceleração atuante sobre o dispositivo é, então, decomposta nesses três eixos e a aceleração da gravidade será a força predominante em qualquer situação. Assim, é possível reconhecer a orientação da tocha de soldagem no espaço, de acordo com o ângulo formado entre cada um dos seus eixos ortogonais e o vetor da aceleração da gravidade. Por conseguinte, quando um dos eixos do equipamento estiver paralelo a este vetor e orientado no mesmo sentido, o ângulo será de zero graus. Em contrapartida, se o eixo estiver orientado no sentido contrário, o ângulo será de 180 graus. Esses dois valores são os limites do intervalo estabelecido, de forma que em qualquer outra orientação, o ângulo medido estará compreendido entre 0 e 180 graus. Portanto, o dispositivo sempre medirá o menor ângulo existente entre o eixo e o vetor da aceleração da gravidade. Como os três eixos são ortogonais, no caso de um deles estar colinear ao vetor da aceleração da gravidade, onde o ângulo será de 0 ou 180 graus, os demais eixos estarão medindo 90 graus.

Ao se conceber o protótipo do dispositivo, por conveniência, definiu-se o eixo Z como colinear ao arame de soldagem. Na Figura 2a é possível observar o sistema de coordenadas de referência da tocha de soldagem quando equipada com o dispositivo. Deste modo, na posição de soldagem plana, o ângulo medido entre o eixo Z e o vetor da aceleração da gravidade é de 0 grau, e na sobre cabeça, de 180 graus. Já na posição de soldagem horizontal, os ângulos medidos tanto em $X$ quanto em $Y$ serão de 90 graus, e na posição vertical, de 180 graus. Isto se deve ao fato da posição da tocha não se alterar em relação ao plano da peça de trabalho, posicionada na vertical. Neste caso, com o sensor utilizado neste trabalho, a única forma de distinguir a posição de soldagem é analisando em qual direção se dá o movimento da tocha. Entretanto, num caso de movimento da tocha com velocidade constante, a única aceleração imposta ao sensor seria a própria gravidade e tendo em vista que o sensor é um acelerômetro, isso resulta no problema descrito anteriormente. Assim, a fim de distinguir entre as posições de soldagem horizontal e vertical, foi estabelecido um padrão para a soldagem na posição $2 \mathrm{G}$ (este se dá com a tocha de soldagem na horizontal), e na posição $3 \mathrm{G}$ (com a tocha de soldagem na vertical), conforme mostra a Figura $2 \mathrm{~b}$ e Figura 2c, respectivamente. Nestas posições de soldagem, o sistema de reconhecimento de posição executa comparações entre os valores obtidos para os eixos X e Z com ângulos limites para cada posição. Salienta-se que o cálculo do ângulo e essa comparação não são discretos, ou seja, abrangem toda a faixa compreendida entre os limites e não apenas pontos específicos.
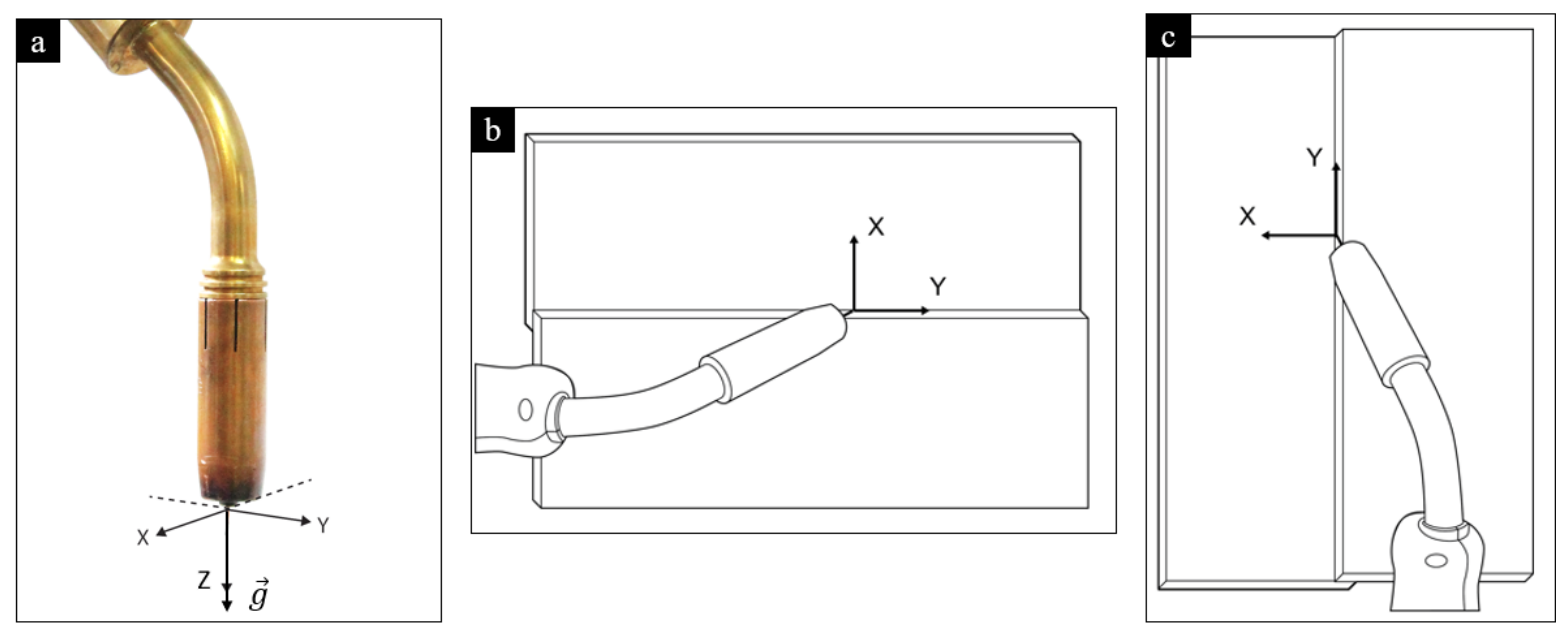

Figura 2. Em (a) sistema de coordenadas de referência para uma tocha de soldagem equipada com o dispositivo. Em (b) orientação padrão da tocha para a soldagem na posição $2 \mathrm{G}$ e em (c) para a posição $3 \mathrm{G}$.

Foi implementada ainda, uma função que possibilita ao soldador escolher qual o modo de operação será empregado pelo dispositivo. A seleção se dá através do acionamento de um botão disponível na IHM do dispositivo, conforme já apresentado na Figura 1a. Os modos de operação diferem entre si, basicamente, em relação aos valores limites dos ângulos que definem cada posição de soldagem. Há dois modos disponíveis: modo LTS (em referência ao Laboratório de Tecnologia da Soldagem, onde o dispositivo foi desenvolvido) e o modo AWS 3.0 (em referência a norma homônima). O primeiro modo funciona com ângulos limitados à 45 graus, sendo que o limite superior de uma posição é o limite inferior da outra posição. Assim, a posição plana está compreendida quando o ângulo medido no eixo Z (do sistema de coordenada) está entre 0 e 45 graus, a posição vertical, por sua vez, quando esse ângulo está entre 45 graus e 135 graus, e por fim, a posição sobre cabeça quando esse ângulo está entre 135 graus e 180 graus. Conforme o padrão adotado, para a soldagem na posição horizontal é considerada a medida do ângulo ao longo do eixo $X$.

O segundo modo de operação é baseado na norma supracitada, cujos limites são estabelecidos pela Figura 3. Não se pôde aplicar criteriosamente a norma em virtude de ela se basear nas posições do cordão de solda e não nas posições da tocha de soldagem. Deste modo, a fim de reconhecer a inclinação do plano de soldagem, adotou-se que a tocha sempre estará perpendicular à peça de trabalho. Assim, a posição plana é definida quando o ângulo medido no eixo $Z$ está entre 0 e 15 graus, 
a posição vertical quando esse ângulo está entre 15 graus e 110 graus, e a posição sobre cabeça quando esse ângulo está entre 110 graus e 180 graus. A posição horizontal respeita o mesmo padrão do outro modo de operação, e é adotada quando o ângulo em $X$ está entre 60 graus e 120 graus.

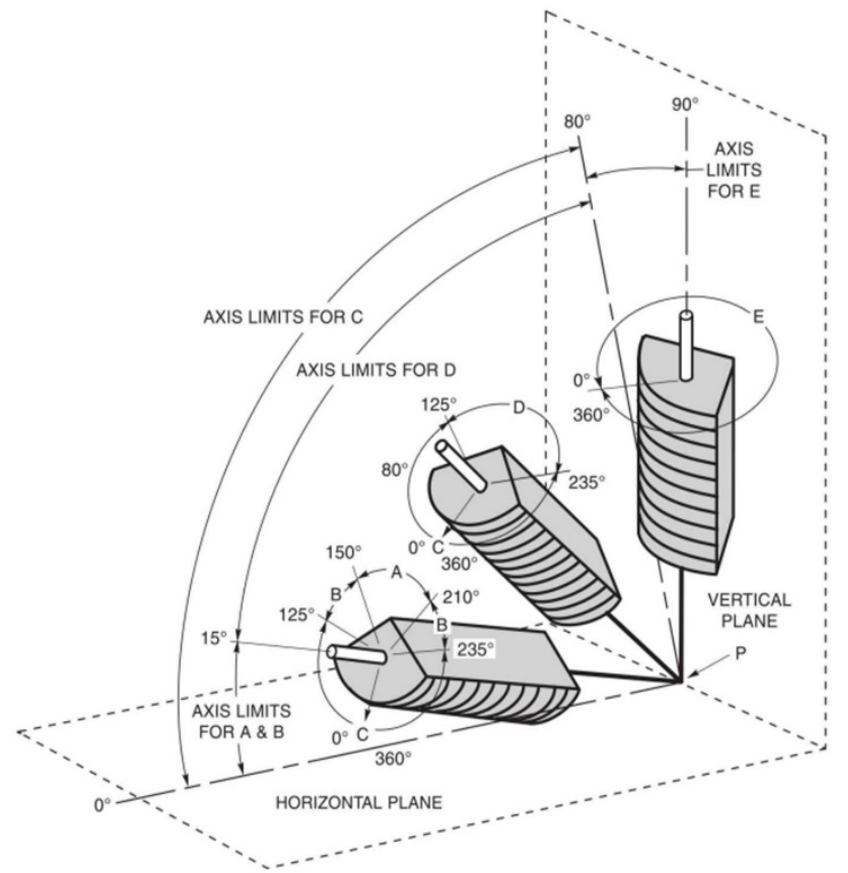

Figura 3. Ângulos limitantes de cada posição de soldagem com referência ao cordão de solda. (AWS [5]).

\subsection{Hardware}

O sistema desenvolvido pode ser subdividido em três partes. O sensor, um acelerômetro responsável por medir a aceleração imposta sobre o dispositivo, um microcontrolador, cuja função é processar os dados lidos e executar os comandos de um algoritmo previamente programado, e a interface homem-máquina (IHM), que tem a tarefa de informar ao operador dados relevantes do processo. Esse dispositivo é acoplado na tocha de soldagem, conforme descrito anteriormente, e se comunica com a fonte de soldagem através de uma porta digital I/O presente na mesma. O microcontrolador utilizado no projeto é o ATMEGA328P montado sobre uma placa de prototipagem eletrônica, denominada Arduino Nano.

O acelerômetro é um sensor inercial, pois é capaz de medir grandezas físicas definidas em um sistema de coordenadas de referência inercial, essa grandeza é a aceleração. A tecnologia empregada nesse sensor é conhecida como Sistemas Microeletromecânicos (MEMS - Micro-Electro-Mechanical Systems), que conforme apresentado por Yazdi et al. [6], é caracterizada pela construção de partes mecânicas integradas com as partes eletrônicas em um mesmo substrato cristalino. Ainda de acordo com o autor, o princípio de funcionamento se resume à medição do deslocamento do corpo de prova interno em virtude da ação da aceleração sobre ele, que pode ser realizada empregando detecção capacitiva, piezoresistiva, piezelétrica, eletromagnética e óptica. O sensor empregado no presente trabalho possui 3 graus de liberdade, armazenando os valores em registradores específicos para os eixos ortogonais $\mathrm{X}, \mathrm{Y}$ e Z. Os dados obtidos são em formato digital, composto por 16 bits para cada eixo, podendo-se escolher a sensibilidade de acordo com os requisitos de projeto tais como: precisão e aceleração máxima. Um fator a ser considerado é o efeito da temperatura do sensor, porém, de acordo com informações do fabricante [7], o acelerômetro utilizado é capaz de operar numa faixa de $-40^{\circ} \mathrm{C}$ a $80^{\circ} \mathrm{C}$. Além disso, os possíveis erros de leitura devido à variação de temperatura são extremamente pequenos e, portanto, podem ser desconsiderados. Isto, somado ao fato de o sensor estar montado dentro do compartimento que, por sua vez, encontra-se junto ao punho da tocha, região esta destinada ao contato com o soldador, onde as temperaturas não são muito elevadas.

Considerando que as fontes de soldagem normalmente apresentam sua própria IHM, contendo os parâmetros de soldagem a serem configurados, optou-se por apresentar na interface do dispositivo apenas, a posição de soldagem atual e qual o modo de operação que está em execução. O ângulo medido de cada eixo do sensor em relação ao vetor da aceleração da gravidade é irrelevante ao soldador. Portanto, a IHM é composta por quatro LEDs referentes a cada uma das quatro principais posições de soldagem de chapas: plana, vertical, horizontal e sobre cabeça, e outro LED indicando qual o modo de operação selecionado. Salienta-se que o projeto do compartimento, que abriga o sensor e a IHM, foi desenvolvido de modo a não alterar o aspecto ergonômico da tocha de soldagem, permitindo-se ao soldador manipulara tocha com a mesma facilidade. 
A fonte de soldagem utilizada na implementação desse projeto é do modelo Digiplus A7-450. Esta possui um modo de operação que permite selecionar, por meio de uma interface digital, os parâmetros de soldagem do processo GMAW, previamente programados em sua memória. A Figura 4 apresenta o fluxograma de funcionamento do hardware do dispositivo desenvolvido neste trabalho. Tanto a comunicação do microcontrolador com a IHM quanto com a fonte de soldagem é realizada por intermédio de sinais digitais, no qual se utilizam cabos com blindagem a fim de evitar interferências eletromagnéticas produzidas pela execução da soldagem. A comunicação entre o sensor e o microcontrolador é realizada através de um protocolo $I^{2} \mathrm{C}$. Como o microcontrolador está instalado dentro do punho da tocha e o sensor na parte externa do mesmo punho (compartimento), a distância entre eles é suficientemente pequena para que não ocorram problemas relacionados aos ruídos eletromagnéticos.

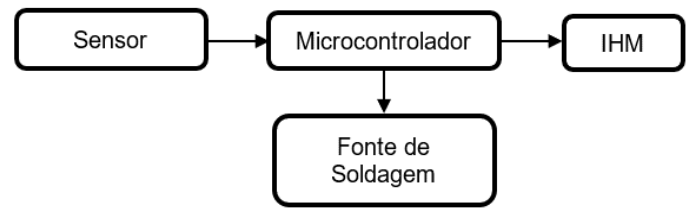

Figura 4. Fluxograma de funcionamento do hardware desenvolvido.

\subsection{Software}

O software embarcado no dispositivo foi desenvolvido em linguagem C. O mesmo é composto pelas funções de setup, loop e funções auxiliares. A função setup é a responsável por inicializar o sensor, os módulos de comunicação e configurar os pinos da I/O do microcontrolador. A função loop é um laço repetido constantemente durante a execução do programa, no qual são chamadas as funções necessárias para a aplicação. As demais funções são as responsáveis por executar a leitura dos dados do sensor, calcular o ângulo de inclinação de cada eixo ortogonal em relação ao vetor da aceleração da gravidade, aplicar métodos de tratamento de dados, verificar o modo de operação relacionado aos limites das posições de soldagem, identificar a posição de soldagem com base nos valores limites dos ângulos, acionar os LEDs da IHM de acordo com a posição atual e se comunicar com a fonte de soldagem para, assim, selecionar o programa de soldagem desejado. A estrutura de funcionamento do software é apresentada no fluxograma da Figura 5.
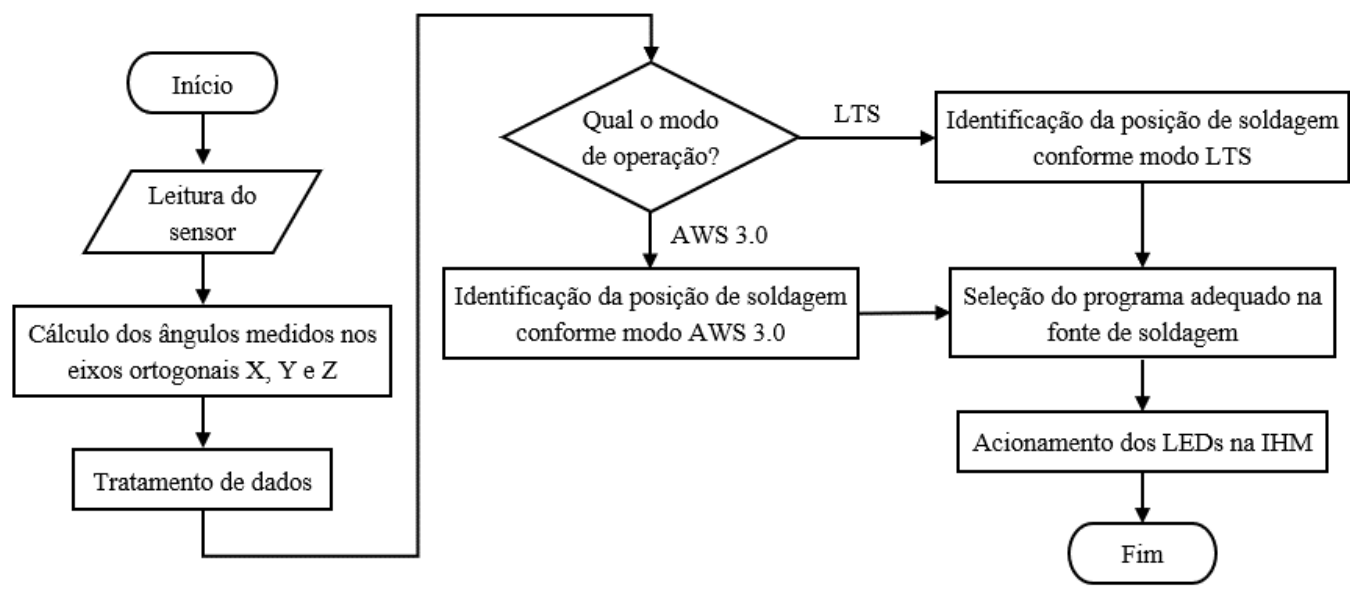

Figura 5. Fluxograma de funcionamento do software embarcado no dispositivo.

A fim de melhorar a experiência do soldador com o dispositivo, foram desenvolvidas outras funcionalidades. Durante a execução da função setup, é verificado na memória do dispositivo qual foi o último modo de operação utilizado, e o sistema é configurado automaticamente na mesma condição. Antes de iniciar a execução da função loop, o sistema realiza um teste de todos os LEDs da IHM, acendendo-os durante um segundo. Isso permite ao soldador verificar se o dispositivo está funcionando adequadamente, além de indicar que a aquisição dos dados da posição de soldagem será iniciada em breve. Além disso, pensando em aplicações acadêmicas, onde poderia ser interessante verificar o ângulo da tocha de soldagem em tempo real, foi desenvolvido uma função que transmite, através de uma porta serial, o tempo (em segundos), a posição de soldagem e os ângulos da tocha medidos em cada um dos seus eixos $\mathrm{X}, \mathrm{Y}$ e Z. Para isso, basta conectar um cabo serial entre o microcontrolador e uma porta USB de um computador com monitor serial. 


\subsubsection{Tratamento de dados}

Tendo em vista que o sensor utilizado é um acelerômetro e que, portanto, realiza a medição da aceleração linear imposta a cada um dos seus três eixos ortogonais, quando o sensor está se movimentando em velocidade constante ou nula, somente a aceleração da gravidade estará agindo sobre o sensor. Nesse caso, espera-se uma leitura de dados em regime estacionário. Porém na prática, os dados obtidos pelo acelerômetro estão sujeitos a ruídos oriundos de interferências internas e externas que impedem que as leituras sejam constantes. A sensibilidade do acelerômetro permite captar, inclusive, vibrações originárias do funcionamento de equipamentos próximos ao ambiente onde o sensor está operando. Deste modo, os ruídos inerentes ao funcionamento do sensor, sobretudo, devido a sua alta sensibilidade, em conjunto com as oscilações do movimento e da posição da tocha de soldagem, provocadas pelo próprio soldador, são capazes de interferir de forma significativa nos dados lidos. Isso pode acarretar na fonte de soldagem ser configurada com os parâmetros de uma posição de soldagem diferente daquela que está em uso. A fim de contornar este problema, foram realizadas simulações de soldagem, procurando-se variar a orientação da tocha de soldagem entre os limites normalmente utilizados pelos profissionais. Com o objetivo de aumentar a robustez do dispositivo desenvolvido, foram executados movimentos relativamente agressivos nessa simulação, a fim de se obter situações piores do que aquelas que o sensor normalmente estará sujeito quando em operação de normal de soldagem.

Com a execução deste procedimento foram obtidos dados da aceleração agindo sobre os eixos do sensor durante 100 segundos, com um intervalo de $200 \mathrm{~ms}$ entre cada leitura, e se calcularam os ângulos referentes a cada eixo ortogonal. Na Figura 6 é apresentado um gráfico com os ângulos de cada eixo e com a posição de soldagem resultante (que seria configurada na fonte). A posição de soldagem é representada em um eixo secundário do gráfico de acordo com o padrão de soldagem para chapas: 1G, 2G, 3G e 4G. Esses dados são chamados de amostra, pois são os valores originais e sem nenhum tratamento. Observa-se a identificação de posições de soldagem inadequadas (IPSI) devido à tamanha variação dos dados obtidos. Isto, numa aplicação prática representa um sério problema, por resultar numa soldagem com parâmetros inadequados para a posição em questão.

Assim, com o objetivo de melhorar o desempenho do dispositivo, mesmo em situações críticas de movimentação, avaliaram-se técnicas para o tratamento dos dados. Neste contexto, o sinal tratado deve atender dois requisitos: alterar corretamente a posição de soldagem (apenas quando houver a transição real de posição da tocha) e possuir uma resposta rápida à transição de posição (em caso de demora, pode acontecer a soldagem com parâmetros inadequados). É interessante, também, que o dado tratado não perca a característica original, ou seja, que as curvas de angulação sejam semelhantes às curvas originais, para uma possível posterior utilização desses valores em outras aplicações. Deste modo, foram avaliadas as técnicas denominadas pelos autores como: filtro complementar (FC), filtro complementar variável (FCV), estrutura de dados tipo fila, histerese e a combinação dessas. Para se estabelecer uma comparação confiável entre os métodos, todos os testes foram aplicados sobre a amostra de dados apresentada na Figura 6.

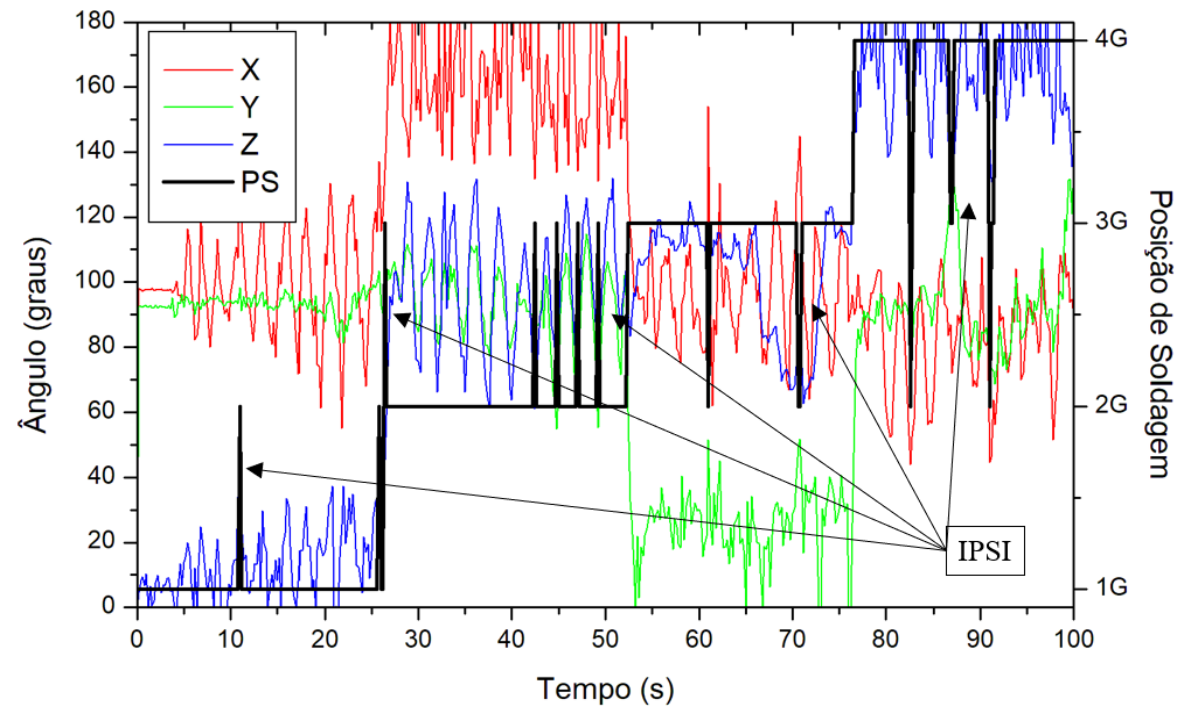

Figura 6. Amostra obtida na simulação de soldagem.

Inicialmente, foi desenvolvido um algoritmo baseado na teoria do filtro complementar, que conforme Bueno e Romano [8], é um método que objetiva a fusão de dados de diferentes sensores a fim de se alcançar uma estimativa ótima de uma determinada variável. Nesse caso, foram fundidos os valores dos ângulos oriundos da leitura atual do sensor com aqueles provenientes da leitura anterior. Denominou-se de fator de amortecimento o valor aplicado aos dados previamente gravados, de forma que o valor imposto aos dados atuais seja complementar ao primeiro, estando ambos no intervalo entre 0 e 1. 
A Equação 1 apresenta a lógica implementada nessa técnica, sendo FA o fator de amortecimento. Com a intenção de se verificar qual o melhor fator de amortecimento, experimentaram-se os valores entre 0,2 e 0,8, com incrementos de 0,1. No gráfico da Figura 7, verifica-se o comportamento da curva original e após a aplicação dos fatores de amortecimento 0,4, 0,6 e 0,8 no intervalo de 20 a 30 segundos para o ângulo do eixo $Z$. Percebe-se que o filtro aplicado com fator de 0,4 suaviza apenas os pontos extremos da curva original, porém, mantém uma flutuação semelhante. Enquanto o filtro com fator de 0,8 apresenta uma suavização acentuada e reduz a oscilação da curva original. No entanto, este fator pode não representar de maneira adequada o comportamento real da angulação do equipamento. Nota-se esse fenômeno com maior facilidade no intervalo entre 25 e 30 segundos, onde a curva do filtro com fator de 0,8 não representa adequadamente o comportamento e a magnitude original dos dados.

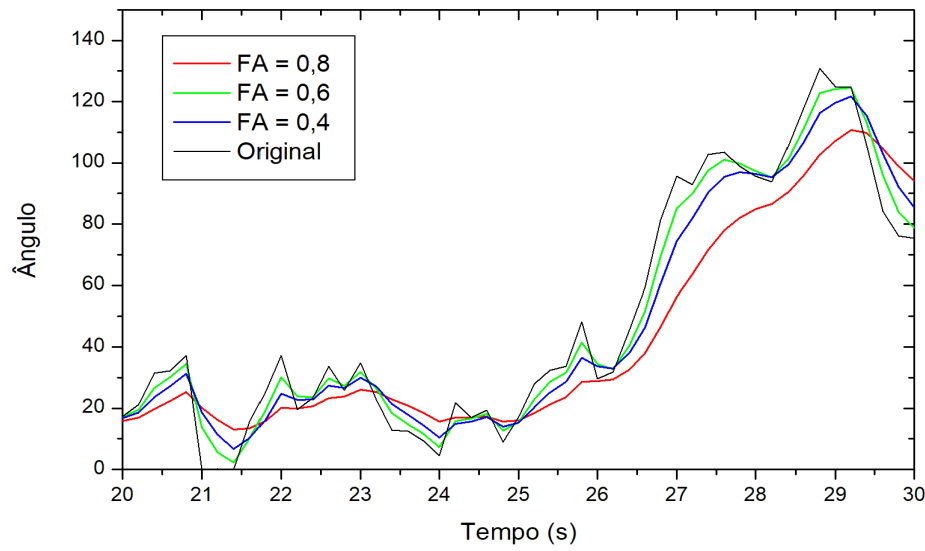

Figura 7. Aplicação do filtro complementar com diferentes fatores de amortecimento nos dados da amostra.

DadoTratado $=(F A *$ Dado Anterior $)+((1-F A) *$ Dado Atual $)$

Com base nos resultados obtidos com o filtro complementar, buscou-se na teoria dos conjuntos e na lógica fuzzy uma forma de aproveitar as vantagens de um fator de amortecimento baixo e alto simultaneamente. A lógica fuzzy permite um raciocínio não exato, onde um valor não precisa ser necessariamente 0 ou 1 , conforme a lógica booleana, mas pode variar dentro desse intervalo. Isso permite, conforme Gomide e Gudwin [9], classificar um determinado dado dentro de um cenário mais qualitativo, onde muitas vezes a transição entre os limites é nebulosa. Baseia-se na teoria fuzzy tendo em vista que anteriormente o mesmo fator de amortecimento foi aplicado para todos os dados, e nessa abordagem se aplica um filtro com diferentes fatores dependendo do quão distante a leitura atual está em relação ao dado anterior. Assim, criou-se um algoritmo capaz de calcular a disparidade entre o último dado lido e o atual. A diferença entre o ângulo atual e o anterior é então classificada como pertencente a um dos diferentes intervalos estabelecidos (menor que 45 graus, entre 45 e 90 graus e maior que 90 graus) e é filtrada de acordo com um fator de amortecimento adequado $(0,2,0,6$ e 0,8 , respectivamente). A esse método, deu-se o nome de filtro complementar variável.

Aprofundando-se nesse conceito do filtro complementar variável, criou-se uma estrutura de dados do tipo fila. Com o intuito de verificar a pertinência de um dado não mais em relação ao último valor lido, mas em relação ao padrão de comportamento anterior do sinal, avaliaram-se alguns comprimentos de fila e definiu-se uma fila com sete posições. Assim, o dado final é o resultado da média aritmética simples entre os sete valores que compõe a fila (últimos sete dados lidos). Dessa forma, caso ocorra um valor espúrio na leitura do sensor, o dado final não responderá de forma tão significativa ao ruído.

Na sequência foi avaliada a fusão do filtro complementar variável com a estrutura do tipo fila. Nesse caso, têm-se as vantagens do filtro complementar variável, capaz de reduzir os ruídos do sinal sem alterar o comportamento do gráfico, somada as vantagens da estrutura de fila, que possibilita comparar a pertinência do dado com um conjunto de leituras anteriores. Assim, aplica-se um filtro ao valor lido pelo sensor dependendo da pertinência dele com a média de um conjunto de dados anteriores. Isso permite que a influência de cada dado seja menor, de modo que um grupo de leituras consecutivas é o fator determinante para a correta identificação da posição de soldagem. Dados com valores não condizentes com esse conjunto, como os originários por ruídos ou movimentos agressivos da tocha, não são percebidos pelo algoritmo que configura os parâmetros de soldagem de acordo com a posição. Porém, no caso da mudança de posição de soldagem pelo soldador, haverá a repetição de um padrão de leituras diferente daquele que vinha sendo obtido. O funcionamento desse algoritmo é exatamente igual ao funcionamento dos dois procedimentos que o compõe e que já foram descritos nesse trabalho. A diferença se dá no ponto de vista de alimentação da fila. Neste caso, têm-se duas vertentes: usar os dados tratados ou os dados originais. A primeira opção parece mais coerente, pois se um dado é pouco condizente com os anteriores não há motivos para lhe colocar na fila. Isso tende a gerar um resultado 
mais estável, mas provavelmente alterará o comportamento e a amplitude do sinal, causando atraso na troca da posição de soldagem.

Para estudar o quão rápido cada método responde a mudança da posição da tocha pelo soldador, criou-se uma transição em degrau de 0 para 90 graus. E se aplicaram as técnicas descritas anteriormente para selecionar aquelas que atendem aos requisitos de projeto. Com base nesses resultados, apresentados na Figura 8, percebe-se que o filtro complementar (com fator de amortecimento 0,8$)$ não atende aos objetivos de projeto. Assim como, o filtro complementar variável em conjunto com a fila alimentada com os dados tratados, que da mesma forma que o filtro complementar com FA igual a 0,8, não atende quanto à resposta necessária para a transição da posição de soldagem. A estrutura de fila e o filtro complementar variável associado à fila alimentada com os dados originais apresentaram o mesmo tempo final de resposta, 1,4 segundos. Porém, a fila mostrou comportamento puramente linear, enquanto a outra técnica apresentou um comportamento linear com diferentes inclinações da reta entre os trechos. Dessa forma, o valor dos ângulos no degrau atinge valores mais altos em um espaço de tempo menor, para o filtro complementar variável associado à fila alimentada com os dados originais (FCV+Fila (amostra)). Tendo como parâmetro a dinâmica de resposta na transição de posição de soldagem, foram considerados apenas os métodos de filtro complementar variável (FCV), estrutura de fila (Fila 7) e filtro complementar variável com a fila sendo alimentada com os dados originais (FCV+Fila (amostra)).

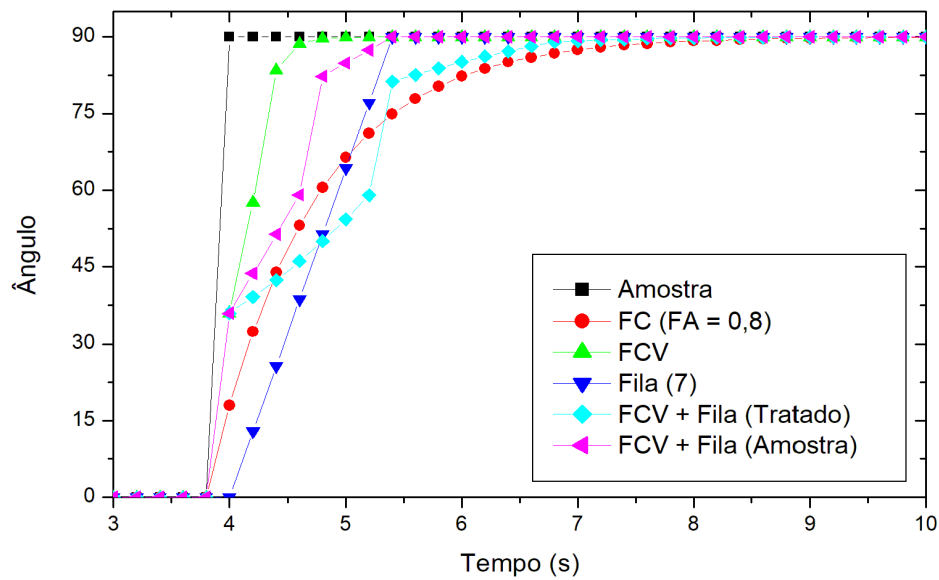

Figura 8. Resposta a uma transição em degrau para diferentes técnicas de tratamento de dados.

A implementação do filtro complementar variável permitiu uma redução da oscilação das curvas sem alterar de forma significativa o comportamento das mesmas e, ainda, reduziu a quantidade de identificações de posições de soldagem inadequadas. Nesse caso, a função do fator de amortecimento baixo é apenas suavizar os picos, enquanto o fator alto é responsável por amortizar os pontos inconsistentes com o comportamento prévio das curvas de angulação. A implementação da estrutura tipo fila aos dados da amostra reduziu apenas uma identificação inadequada da posição de soldagem. Entretanto, esse método produz uma mudança sensível no comportamento das curvas de angulação dos eixos, devido ao uso da média aritmética simples no cálculo. Em geral, o emprego da média dos valores resulta em dados precisos, mas não exatos, como neste caso. Com base nisso, essa técnica foi desconsiderada em vez que será difícil utilizar os dados tratados posteriormente numa possível aplicação onde se deseja medir a angulação da tocha de soldagem, por exemplo. Os dados tratados pela aplicação do filtro complementar variável associado à estrutura de fila alimentada com os dados provenientes da amostra apresentou os melhores resultados. Entretanto, esta solução não se mostrou capaz de eliminar de forma plena a identificação de posições de soldagem inadequadas (IPSI). Com base nisso, aplicou-se a esta solução a técnica de histerese. Deste modo, o funcionamento do algoritmo não se baseia apenas nos ângulos limites de cada posição, mas, considera também qual a posição de soldagem no instante antecedente. Dessa forma, para que haja a transição de uma posição de soldagem, o movimento real da tocha deverá superar não somente o ângulo limite, mas um valor de tolerância estabelecido. Isso dá origem a uma janela no intervalo de dados, onde não ocorrerá a comutação de posição de soldagem, sendo imprescindível para aqueles casos onde a soldagem ocorre com a tocha posicionada próximo dos limites de determinada posição. Essa tolerância foi definida como \pm 5 graus.

O resultado após a aplicação da solução descrita é exibido na Figura 9. Ao comparar esse resultado com os dados da amostra (dados originais do sensor apresentados na Figura 6), percebe-se que o comportamento das curvas de angulação de cada eixo pouco se altera em relação ao original. Além disso, é importante salientar a inexistência de identificação da posição de soldagem inadequada durante todo o ensaio. 


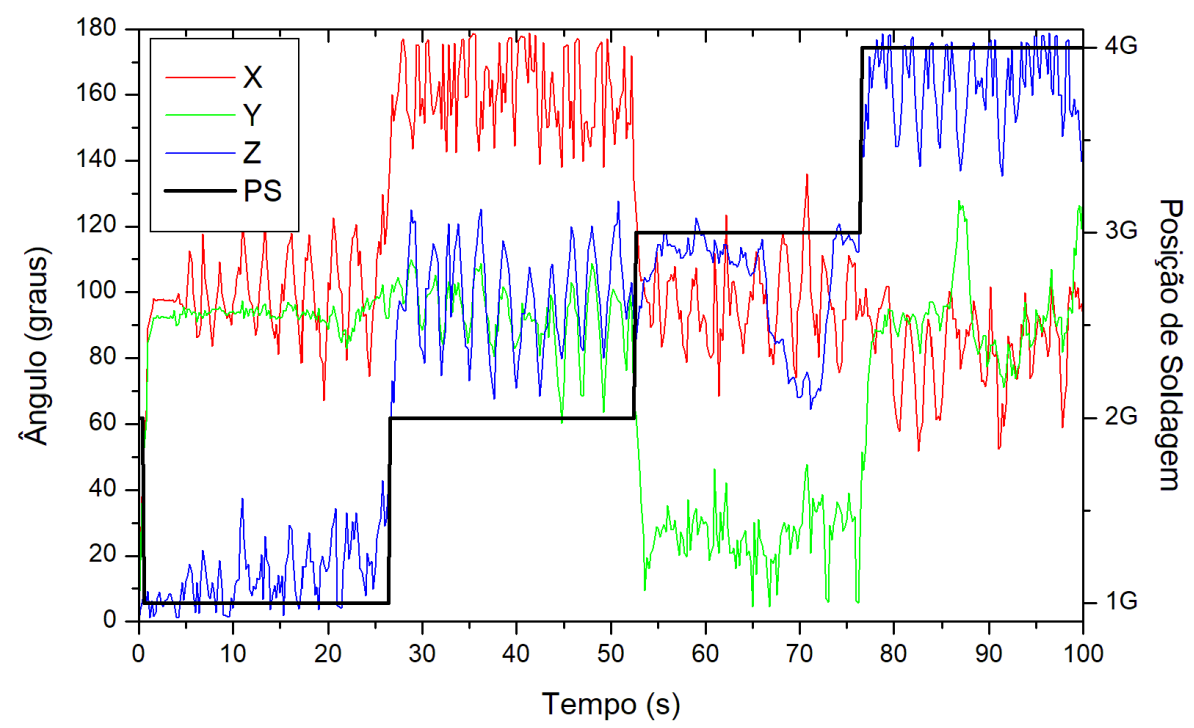

Figura 9. Resultado do filtro complementar variável associado à fila alimentada com a amostra em funcionamento com a histerese.

\section{Ensaio de Soldagem}

Com o intuito de avaliar o funcionamento do dispositivo desenvolvido neste trabalho, foram realizados ensaios de soldagem de forma manual. Nestes ensaios a posição da tocha foi alterada produzindo, assim, cordões de solda em diferentes posições de soldagem. Para cada uma das quatro principais posições de soldagem (1G, 2G, 3G e 4G), foram definidos diferentes parâmetros de soldagem GMAW, apresentados na Tabela 1. Foram realizados cordões de simples deposição sobre chapas de aço carbono ABNT 1020, montadas de modo a simular a aplicação típica na construção de um bloco de construção naval. $O$ arame utilizado foi o ER70S-6, com diâmetro de $1,0 \mathrm{~mm}$, e o gás de proteção $\mathrm{Ar}+5 \% \mathrm{O}_{2}$, com vazão de $15 \mathrm{~L} / \mathrm{min}$. A sequência das posições de soldagem empregadas foi: plana, vertical ascendente, horizontal, novamente vertical ascendente e sobre cabeça, tal como mostrado na Figura 10. O modo de operação do dispositivo utilizado foi o LTS.

Tabela 1. Parâmetros utilizados no ensaio de soldagem.

\begin{tabular}{ccc}
\hline Posição de soldagem & Modo de transferência metálica & Parâmetros do processo \\
\hline $1 G$ & Pulsado - modo sinérgico & $\mathrm{Im}=150 \mathrm{~A}$ \\
$2 \mathrm{G}$ & Curto circuito & $\mathrm{V}=21 \mathrm{~V}, \mathrm{Va}=6 \mathrm{~m} / \mathrm{min}$ \\
$3 G$ & Pulsado - modo sinérgico & $\mathrm{Im}=80 \mathrm{~A}$ \\
$4 \mathrm{G}$ & Curto circuito & $\mathrm{V}=18,5 \mathrm{~V}, \mathrm{Va}=3,5 \mathrm{~m} / \mathrm{min}$ \\
\hline
\end{tabular}

Os gráficos apresentados na Figura 11 mostram a transição da posição de soldagem, os valores dos ângulos medidos nos eixos ortogonais $\mathrm{X}, \mathrm{Y}$ e Z e o comportamento da corrente de soldagem ao longo do tempo. A corrente de soldagem foi medida com o sistema de aquisição de dados SAP V4, enquanto os dados da posição de soldagem e ângulos foram obtidos pelo próprio microcontrolador conectado a uma porta serial de um computador. A transição correta da posição de soldagem em cada segmento da trajetória proposta e as curvas suaves dos ângulos medidos nos três eixos do sistema de coordenadas revelam que as técnicas de tratamento de dados implementadas no software funcionaram de acordo com o esperado. A alteração nos respectivos parâmetros de soldagem pode ser vista pela análise dos gráficos da corrente de soldagem em destaque. Além disso, ao se comparar a ocorrência da transição da posição de soldagem com a aquisição dos ângulos, percebe-se o funcionamento da técnica de histerese que acrescenta a tolerância preestabelecida aos limites dos ângulos. Conforme esperado, isso permitiu soldar com os parâmetros adequados nas regiões de transição entre as posições: plana e vertical, e vertical e sobre cabeça, conforme a trajetória mostrada na Figura 11. Por fim, observa-se ainda a diferença entre as curvas de angulação dos eixos $X, Y$ e $Z$ entre esse ensaio de soldagem e os da amostra, mostrados na Figura 6 . Isso mostra que os movimentos de soldagem realizados em uma aplicação real são mais suaves do que aqueles que foram a fonte da implementação do software, caracterizando a robustez do projeto pela qual se prezou durante o desenvolvimento. 


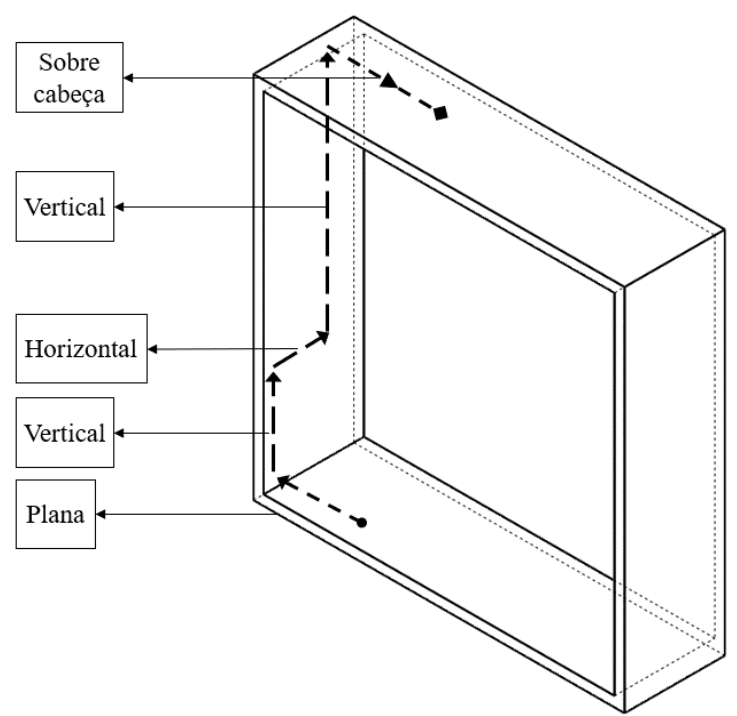

Figura 10. Trajetória de soldagem realizada nos ensaios de soldagem.
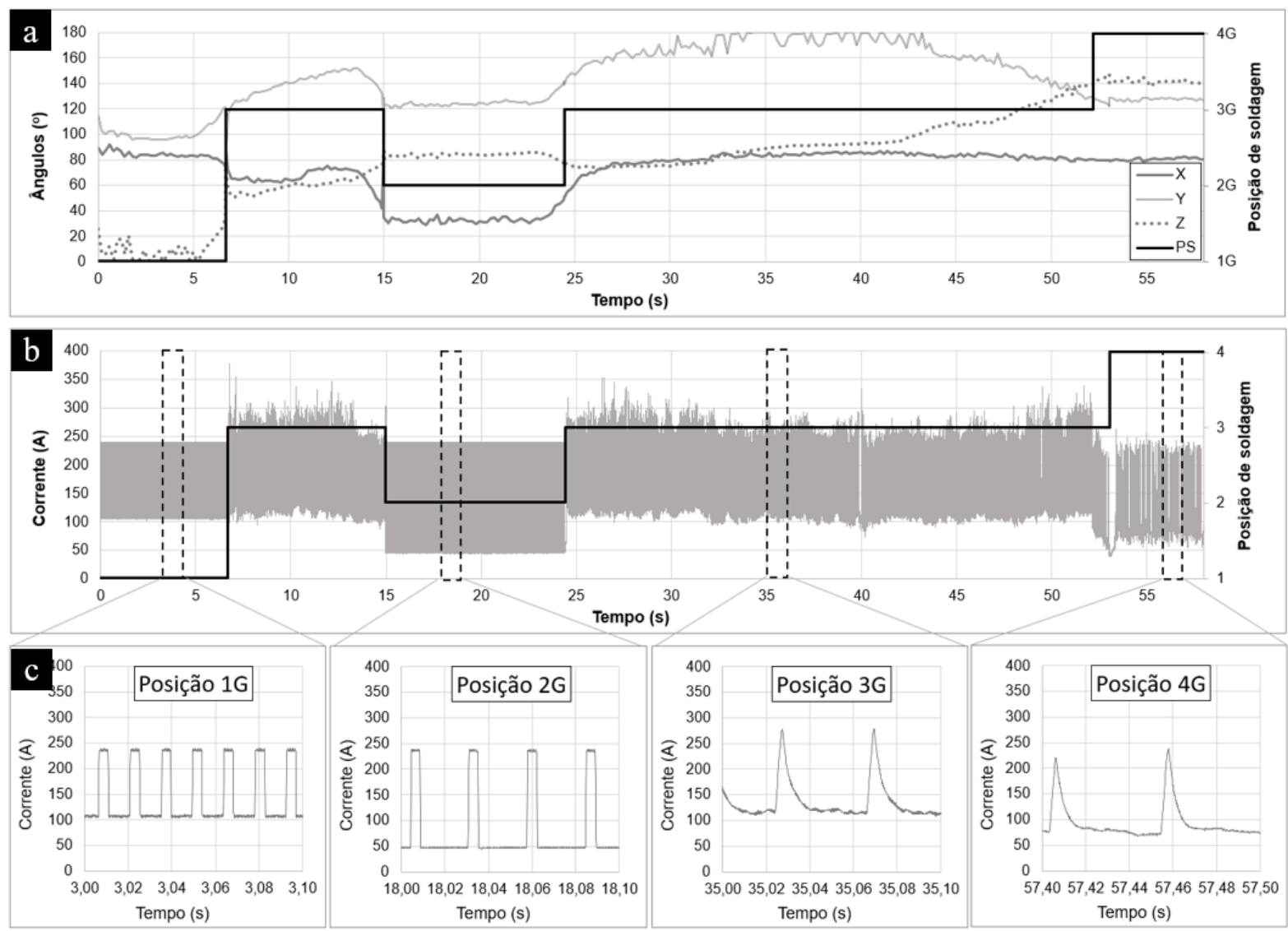

Figura 11. Ensaio de soldagem. Aquisições (a) dos ângulos medidos nos eixos ortogonais $X, Y$ e Z e (b) da corrente de soldagem. $\mathrm{Em}$ (c) aquisições da corrente em cada posição de soldagem.

\section{Conclusões}

Com a realização deste trabalho, pode-se concluir que:

- É possível que uma tocha de soldagem reconheça a posição no qual a soldagem está sendo executada;

- O protótipo desenvolvido foi capaz de identificar a posição da tocha e se comunicar com a fonte de soldagem, conseguindo selecionar automaticamente os parâmetros do processo com base em variáveis pré-estabelecidas na fonte de soldagem;

- Para a correta identificação da posição de soldagem 2G, essa se dá com a tocha de soldagem posicionada na horizontal, enquanto na posição $3 G$ a tocha deve estar na vertical; 
- $\quad$ estudo sobre os métodos de tratamento de dados permitiu determinar o algoritmo com o melhor desempenho, capaz de identificar corretamente a posição de soldagem mesmo em situações críticas de movimentação;

- A solução desenvolvida para o tratamento de dados do sensor permitiu ao dispositivo alterar corretamente a posição de soldagem, obtendo uma rápida resposta a transição sem, entretanto, comprometer o comportamento das curvas de angulação.

\section{Agradecimentos}

Os autores agradecem ao LTS - Laboratório de Tecnologia da Soldagem da Universidade Federal de Santa Catarina, campus Joinville - pelo espaço físico, apoio e auxílio no desenvolvimento deste trabalho e à empresa IMC Soldagem.

\section{Referências}

[1] Mandić I, Domazet Ž, Stipaničev D. Introduction of welding robots in shipyards. Advanced Robotics. 1988;3(1):35-51. http://dx.doi.org/10.1163/156855389X00163.

[2] Niculescu Al, D'haro LF, Banchs RE, Yeo KH, Vyas D. Understanding welding practices on shipyards: An ethnographic study for designing any interactive robot welder. In: IEEE. Proceedings of the 3rd IEEE International Conference on User Science and Engineering; 2014 Sept. 2-5; Shah Alam, Malaysia. New Jersey: IEEE; 2014. p. 1-6.

[3] Ang JR, Marcelo H, Lin W, Lim, S-Y. A walk-through programmed robot for welding in shipyards. Industrial Robot. International Journal. 1999;26(5):377-388.

[4] Li X, Lu Y, Zhang YM. Accelerometer-based position and speed sensing for manual pipe welding process. International Journal of Advanced Manufacturing Technology. 2013;69(1-4):705-713. http://dx.doi.org/10.1007/s00170-013-5056-0.

[5] American Welding Society. ANSI/AWS A3.0-94: standard welding terms and definitions. Miami: AWS; 1994.119 p.

[6] Yazdi N, Ayazi F, Najafi K. Micromachined inertial sensors. Proceedings of the IEEE. 1998;86(8):1640-1659. http://dx.doi.org/10.1109/5.704269.

[7] InvenSense. MPU-6000/MPU-6050 Product Specification. Sunnyvale: InvenSense; 2013. 52 p.

[8] Bueno AG, Romano RA. Filtro complementar aplicado a medida de inclinação de plataformas móveis [tese iniciação científica]. S.I.: Instituto Mauá de Tecnologia, Conselho Nacional de Desenvolvimento Científico e Tecnológico; 2014.

[9] Gomide FAC, Gudwin RR. Modelagem, controle, sistemas e lógica fuzzy. SBA Controle \& Automação. 1994;4(3):97-115. 